\title{
A educação básica brasileira em disputa: doutrinação versus neutralidade
}

\author{
Ana Cláudia Rodrigues de Oliveira ${ }^{1}$ \\ https://orcid.org/0000-0003-3433-6074
}

Fabio Lanza ${ }^{2}$

https://orcid.org/0000-0003-2807-9075

\author{
Letícia Jovelina Storto ${ }^{3}$ \\ http://orcid.org/0000-0002-7175-338X
}

\begin{abstract}
${ }^{1}$ Secretaria de Estado da Educação do Paraná, Departamento de Ciências Sociais, Ensino Médio, Londrina, PR, Brasil.
${ }^{2}$ Universidade Estadual de Londrina, Departamento de Ciências Sociais, Programa de Pós-Graduação em Ciências Sociais, Londrina, PR, Brasil.

${ }^{3}$ Universidade Estadual do Norte do Paraná, Centro de Letras, Comunicação e Artes, Programa de Pós-Graduação em Ensino, Cornélio Procópio, PR, Brasil.
\end{abstract}

\begin{abstract}
A educação básica brasileira em disputa: doutrinação versus neutralidade
Resumo: A partir da investigação sobre os principais fundamentos ideológicos e pressupostos da organização associativa Escola sem Partido (ESP), com sede na cidade de São Paulo, este trabalho busca analisar as implicações das perspectivas e pautas defendidas pela associação para a educação e à sociedade brasileira na última década, abrangendo, mais especificamente, seus desdobramentos no âmbito do ensino da Sociologia no nível médio da educação básica. A pesquisa documental ocorreu junto aos meios de comunicação, eletrônicos e impressos, websites e redes sociais vinculadas ao ESP e abordadas a partir de contribuições da análise crítica do discurso. Como resultado, destacamos os conceitos de doutrinação ideológica e neutralidade do ensino propostos pelo ESP, seus temas e pautas que recaem sobre a questão do cerceamento da prática docente e aos componentes curriculares da disciplina de Sociologia, admitida apenas, quando se aproxime dos padrões nomotéticos de um conhecimento sociológico positivista e cientificista, reprodutores do seu projeto societário conservador.
\end{abstract}

Palavras-chave: Escola sem Partido. Ensino de Sociologia. Currículo.

\section{The Brazilian Basic Education in Dispute: Indoctrination vs. Neutrality}

Abstract: This study examined the main ideological foundations and assumptions of the organization Escola sem Partido (School without Party) (ESP), based in the city of São Paulo, Brazil. This article discusses the implications of the perspectives and guidelines regarding education and society defended by the organization in the last decade, highlighting, more specifically, the developments of the debate in sociology teaching in high school. Documentary research collected electronic and printed material from the press, websites, and social media linked to ESP, which was studied using critical discourse analysis. The results highlight the concepts of ideological indoctrination and neutrality of teaching proposed by ESP, as well as the topics and agenda related to the issue of the curtailment of teaching practice and curricular components of the discipline of sociology. For the ESP, sociology could only be admitted when reflecting nomothetic standards of a positivist and scientific sociological knowledge, reproducing the organization's project of a conservative society.

Keywords: School without party. Sociology teaching. Curriculum.

Recebido em 01.02.2019. Aprovado em 16.04.2019. Revisado em 12.07.2019.

(C) O(s) Autor(es). 2019 Acesso Aberto Esta obra está licenciada sob os termos da Licença Creative Commons Atribuição-NãoComercial 4.0 Internacional (https://creativecommons.org/licenses/by-nc/4.0/deed.pt_BR), que permite copiar, distribuir e reproduzir em qualquer meio, bem como adaptar, transformar e criar a partir deste material, desde que para fins não comerciais e que você forneça o devido crédito aos autores e a fonte, insira um link para a Licença Creative Commons e indique se mudanças foram feitas. 


\section{Introdução}

O movimento Escola sem Partido (ESP) se autoidentifica como uma iniciativa conjunta de estudantes, pais e professores articulados para ações e estratégias de combate a um suposto quadro de "[...] contaminação político-ideológica [...]" (NAGIB, 2008) dos diferentes níveis do ensino básico brasileiro que, sustentado pelo pretex to do ensino de visões críticas sobre a realidade social, enviesaria o sistema educacional brasileiro para uma doutrinação política de esquerda.

Essa organização foi fundada em 2004, pelo advogado Miguel Nagib, que teria se inspirado em movimentos similares organizados nos Estados Unidos (EUA), como, por exemplo, o No Indoctrination. Em entrevista cedida ao blog Portaberta e publicada pela página Mídia sem Máscara, o líder da organização explica suas motivações:

A ideia de uma "escola sem partido" - o que é, na verdade, um conceito ideal - surgiu como reação ao fenômeno da instrumentalização do ensino para fins político-ideológicos e partidários. É fato notório que, nos últimos 30 anos, um número cada vez maior de professores e autores de livros didáticos vem se utilizando de suas aulas e de suas obras para doutrinar ideologicamente os estudantes, visando à formação e propagação de uma mentalidade social favorável a partidos e organizações de esquerda. (NAGIB, 2008).

Há de se pontuar ainda, que, o problema da doutrinação político-ideológica no âmbito do ensino não é denunciado como uma exclusividade da atual conjuntura nacional, pelo contrário, estaria em curso por todo o mundo, afetando também o sistema educacional de países como Venezuela, Portugal, França, Cuba, Itália e Espanha - segundo publicações feitas no website Escola sem Partido na aba sobre Doutrinação no Mundo (ESCOLA SEM PARTIDO, [200-?a]).

Diante de tal denúncia, que indica a existência criminosa de uma doutrinação ideológica em escala internacional, a Escola sem Partido afirma ser "[...] uma associação informal, independente, sem fins lucrativos e sem qualquer espécie de vinculação política, ideológica ou partidária" (NAGIB, 2008), que possui dentro de suas ações a identificação e denúncia dos respectivos criminosos.

Por meio da disseminação de orientações sobre como flagrar e denunciar professores doutrinadores, da disponibilização de modelos de notificação extrajudicial e da elaboração de projetos de lei para instâncias municipais, estaduais e, federal, a ESP estaria engajada em combater a doutrinação, garantir a neutralidade do ensino, o pluralismo de ideias e proteger o estudante - tido como parte frágil e vulnerável do processo de ensino-aprendizagem. Nota-se também esforços para colocar em descrédito intelectuais socialistas, sobretudo, aqueles enquadrados na tradição marxista:

Sob o pretexto de transmitir aos estudantes uma "visão crítica" da realidade, esses professores e autores se prevalecem da liberdade de cátedra, da cortina de segredo das salas de aula, da imaturidade, da inexperiência e da falta de conhecimento dos alunos para impingir-lhes a sua própria visão de mundo, quase sempre identificada com a perspectiva marxista. (NAGIB, 2008).

Faz-se necessário, portanto, problematizar neste trabalho a adaptação dos conceitos de doutrinação, neutralidade e apartidarismo, que servem de instrumento a diferentes modalidades de ação e que aparecem nas pautas defendidas pela ESP. Para Frigotto (2016, p. 12), a Escola sem Partido está longe de ser neutra e apartidária, pelo contrário, trata-se:

[...] da escola do partido absoluto e único: partido da intolerância com as diferentes ou antagônicas visões de mundo, de conhecimento, de educação, de justiça, de liberdade; partido, portanto da xenofobia nas suas diferentes facetas: de gênero, de etnia, da pobreza e dos pobres etc.

Como veremos mais adiante, há uma oposição entre as perspectivas e pautas da ESP e os temas relativos às diversidades socioculturais e interculturalidade, bem como a outros temas comuns nas diretrizes $\mathrm{e}$ nos currículos da disciplina de Sociologia. Destacamos aqui, que o Projeto de Lei no 867 de 2015 (BRASIL, 2015), que dispõe sobre a inclusão do Programa Escola sem Partido na Lei de Diretrizes e Bases da Educação Nacional (LDBEN) de 1996, é de autoria do deputado federal Izalci Lucas (PSDB-DF), mesmo deputado responsável pela formulação do Projeto de Lei ${ }^{\circ} 6.003$ (BRASIL, 2013), apresentado no ano de 2013, com o intuito de retirar a obrigatoriedade do ensino das disciplinas de Sociologia e Filosofia no Ensino Médio.

A problematização central deste artigo desdobra-se em duas questões norteadoras: (a) como o ensino de Sociologia aparece nas produções e perspectivas compartilhadas por membros da organização Escola sem 
Partido? (b) de que modo os componentes curriculares da disciplina de Sociologia no Ensino Médio são abordados nas pautas defendidas pela associação?

Por meio da pesquisa documental e da análise crítica do discurso (ACD), este trabalho investiga o modo como o ensino de Sociologia é abordado nos conteúdos veiculados pela ESP, tomando como fonte principal as produções textuais e audiovisuais disponibilizadas por associados no próprio website da organização e recorrendo também aos artigos, matérias e entrevistas cedidas a revistas ou jornais eletrônicos.

A metodologia da ACD pode ser entendida como uma apropriação da análise discursiva para complementação de outras técnicas em pesquisa social, ou seja, uma abordagem sociodiscursiva capaz de estabelecer conexões com as relações de poder e com os fundamentos ideológicos da ação discursiva (RAMALHO, 2005; SCHNEIDER; TAVARES, 2013).

A partir dessas contribuições coube-nos questionar qual seria a perspectiva mais geral da organização ESP sobre o ensino da disciplina de Sociologia e, sobretudo, quais as contradições entre a fundamentação e pressupostos ideológicos do grupo e os conteúdos que compõem a atual grade curricular da disciplina - aos quais há constante referenciamento. Tais questões serão analisadas levando em consideração o quadro histórico mais amplo dos avanços e recuos para a institucionalização da Sociologia no Ensino Médio no Brasil.

\section{A sociologia no ensino médio: uma história intermitente}

O processo de institucionalização da disciplina de Sociologia enquanto componente curricular obrigatório para o Ensino Médio no Brasil possui uma trajetória marcada por constantes avanços e recuos, marcada não só pelas relações sociais de poder e dominação, conflitos e disputas que permeiam o âmbito educacional do País, como demonstram as Diretrizes Curriculares Estaduais de Sociologia (PARANÁ, 2008), mas também por tensões internas das próprias Ciências Sociais e da Sociologia (MORAES, 2011). Na Reforma Educacional de Benjamin Constant, realizada no ano de 1890, localiza-se a primeira tentativa de tornar obrigatório o ensino da Sociologia. Porém, a disciplina não foi institucionalizada na prática:

[...] a Reforma Benjamim Constant, que entre outras coisas tornava obrigatório o ensino da disciplina, nem chegou a vingar devido a desentendimentos entre o autor e o marechal-presidente, morrendo o ministro pouco depois de se iniciar o governo constitucional do qual nem fez parte. Por outro lado, o alcance da obrigatoriedade não ultrapassava a sede do governo [...], pois a legislação federal, no caso - instrução pública -, se restringia a instituições federais, tendo em vista a quase absoluta autonomia dos Estados. (MORAES, 2011, p. 361).

Com a reforma educacional João Luiz Alves (1925) - também conhecida como Reforma Rocha Vaz a Sociologia é incluída entre as disciplinas do ensino secundário, através do Decreto $\mathrm{n}^{\circ} 16.782$-A de 13 de janeiro de 1925 (BRASIL, [1991]) - revogado integralmente no ano de 1991. No entanto, outra reforma educacional, a Reforma Capanema (1942, Lei Orgânica do Ensino Secundário), consegue banir novamente a disciplina dos componentes curriculares. A Lei vigorou até 1961, quando foi aprovada a Lei de Diretrizes e Bases da Educação Nacional (LDBEN), instituída pela Lei no 4.024/61 (BRASIL, [2019a]) - que colocava a Sociologia enquanto disciplina optativa (CIGALES;ARRIADA, 2013). Com a Ditadura Militar no Brasil (19641985), a Sociologia perde espaço gradualmente, sendo substituída pelas disciplinas de Educação Moral e Cívica e Ordem Social e Politica Brasileira no ano de 1969, ambas voltadas à legitimação do regime militar e da Doutrina de Segurança Nacional, como demonstram Nunes e Rezende (2008).

É apenas a partir do fim do período da ditadura militar brasileira, com o início da abertura democrática, que a disciplina retorna aos poucos aos currículos, enfrentando, porém, as dificuldades resultantes de seus processos descontínuos de institucionalização, como aponta Vargas (ca. 2010, p. 4):

A consequência dessa intermitência e descontinuidade é um acúmulo limitado de experiências didáticopedagógicas e uma restrita produção de pesquisas e de materiais adequados ao ensino. Nas escolas, essa ausência histórica se reflete não só na falta de professores e na dificuldade de encontrar estratégias pedagógicas adequadas, mas na limitada "legitimidade" da mesma no interior do espaço escolar.

Com a LDBEN de 1996, Lei no 9.394/96 (BRASIL, 2019b) o ensino da Sociologia volta a ser discutido, mas não há definições claras de seus conteúdos, objeto e seu papel para a educação nacional. Por isso em 1997, o deputado federal Padre Roque, propõe o Projeto de Lei da Câmara nº 9/2000 (BRASIL, 2000b), que com base na Lei n ${ }^{\circ}$ 9.394/96 previa o domínio dos conteúdos da Sociologia e da Filosofia como fundamentais ao 
exercício da cidadania. Este projeto foi aprovado no ano de 2000, contudo recebeu o veto de Fernando Henrique Cardoso (MORAES, 2011).

Em 1998, as Diretrizes Curriculares Nacionais (DCN) trazem uma alteração negativa: dispõem a Sociologia enquanto conteúdo complementar de caráter interdisciplinar, associando a mesma ao papel de desenvolvimento de competências e negando à disciplina o status de ciência autônoma:

[...] o Conselho Nacional de Educação (CNE) regulamentou os artigos da LDB referentes ao ensino médio com a edição das Diretrizes Curriculares Nacionais do Ensino Médio (DCNEM), Parecer CNE/CEB n. 15/98 e Resolução CNE/CEB n. 03/98. Nesses documentos, ficou estabelecido que o tratamento a ser dado aos conhecimentos da Sociologia e Filosofia seria interdisciplinar, o que reforçou a campanha pela aprovação do projeto do Padre Roque, que ia em sentido contrário. (MORAES, 2011, p. 370).

Os Parâmetros Curriculares Nacionais (PCNEM), de 1999 (BRASIL, 2000a), seguindo as orientações destas DCN (BRASIL, 1998) inferiram que não seria preciso garantir o ensino obrigatório específico da disciplina, mas sim o desenvolvimento de suas competências, por meio da abordagem multidisciplinar de outras ciências humanas. A disciplina de Filosofia foi submetida a essas mesmas condições. No ano de 2004, a convite da professora Heloisa Helena T. de Souza Martins, uma equipe composta pelo professor Amaury Cesar Moraes, professora Ileizi Luciana Fiorelli Silva e Clarissa Baeta Neves realizam uma sessão especial para a discussão sobre o ensino de Sociologia na Reunião Anual da Sociedade Brasileira para o Progresso da Ciência (SBPC) (MORAES, 2011).

Ao contribuírem no processo de reformulação das diretrizes, esses professores questionaram acerca da obrigatoriedade da disciplina, fazendo, assim, com que o MEC assumisse o compromisso de encaminhar a proposta de lei para a inclusão das disciplinas de Sociologia e Filosofia, elaborando o parecer que fundamentou a Resolução no 38/06 (BRASIL, 2006) o Conselho Nacional de Educação.

Essa equipe de elaboradores das novas Orientações Curriculares Nacionais, coordenada pelo prof. Amaury César de Moraes, provocou um debate no interior do MEC. Em 2005, Moraes elaborou um Parecer detalhado sobre a legislação educacional, desde a LDB de 1996 até as DCNEM (1998). Nesse Parecer consegue explicitar que as Diretrizes Curriculares Nacionais do Ensino Médio de 1998 não estavam cumprindo a LDB, pois não garantia que os currículos, de fato, ofereceriam os conhecimentos de Filosofia e de Sociologia, apenas como temas transversais. (SILVA, 2007, p. 420, grifo do autor).

Com a Resolução no 38/06 (BRASIL, 2006), o Conselho Nacional de Educação acata a obrigatoriedade das duas disciplinas, para todas as escolas públicas e privadas do país. Entretanto, como já havia sido indicado por Silva (2007, p. 421), a disciplina ainda enfrentaria alguns embates:

[...] a inclusão da sociologia e a efetividade do seu ensino dependerá do modelo de ensino médio, de currículo e de financiamento que serão vitoriosos no desfecho dos embates. Eu penso que a sociologia teria mais chances de consolidação como disciplina escolar em currículos científicos, para um ensino médio de formação integrada e com financiamento federal e estadual garantido. Ao contrário, a sociologia seguirá instável, entrando de diferentes formas nos currículos dos Estados ou dos municípios, em provas de alguns vestibulares, enfim, a fragmentação persistirá.

No ano de 2008, as disciplinas de Sociologia e Filosofia tornam-se obrigatórias, por meio da Lei n ${ }^{\circ} 11.684$ (BRASIL, [2008]), que oficializa a institucionalização da disciplina nas grades curriculares do Ensino Médio. Apesar desta lei e da inserção da disciplina ocorrida no ano de 2009, nem todos os estados cumpriram prontamente esta determinação.

No Paraná, a obrigatoriedade do ensino de Filosofia e Sociologia foi regulamentada pela Lei no 15.228 de julho de 2006 (PARANÁ, [2006]) e o estado foi considerado pioneiro nas lutas pela institucionalização. Já o estado de São Paulo, por exemplo, foi um dos últimos a cumprir esta legislação educacional, conseguindo ampliar este processo a partir do ano de 2012. Ainda assim, o currículo do Estado orienta-se pelas Diretrizes Curriculares Nacionais para o Ensino Médio (DCNEM) anterior, e resiste à adesão às Orientações Curriculares para o Ensino Médio (OCEM) - Sociologia (SILVA, 2010).

Fica em evidência que a institucionalização da disciplina no Ensino Médio brasileiro é uma história de intermitências, avanços e recuos sucessivos. Tal descontinuidade não se findou com a obrigatoriedade da disciplina: são constantes os embates sobre a permanência da obrigatoriedade das disciplinas de Sociologia e Filosofia no currículo do Ensino Médio. 
Em 2013, o deputado federal Izalci Lucas Ferreira (PSDB-DF) formulou o Projeto de Lei no 6.003/2013 (BRASIL, 2013), o qual previa a retirada da Sociologia e da Filosofia dos currículos, voltando a considerá-las como competências a serem desenvolvidas de modo interdisciplinar. O Projeto de Lei provocou ampla mobilização entre educadores e foi rejeitado em novembro do mesmo ano.

A tentativa de tramitação deste projeto na Comissão da Educação revela a articulação de forças políticas conservadoras à qual as disciplinas de Sociologia e Filosofia desafiam em diferentes momentos históricos. Cabe aqui observar a necessária conjugação das lutas e resistências de educadores das duas disciplinas, como ocorreu, por exemplo, na formulação das Orientações Curriculares para o Ensino Médio.

Como já apontado, Izalci Lucas é também o autor do Projeto de Lei no 867/15 (BRASIL, 2015), articulado pela organização Escola sem Partido, cuja redação dispõe que a educação nacional deve garantir sua neutralidade política, ideológica e religiosa, a pluralidade de ideias, a liberdade de aprendizagem e de crença e o direito dos pais de educar moralmente os filhos conforme suas convicções particulares. O Artigo n. 2 do projeto apresenta os seguintes princípios:

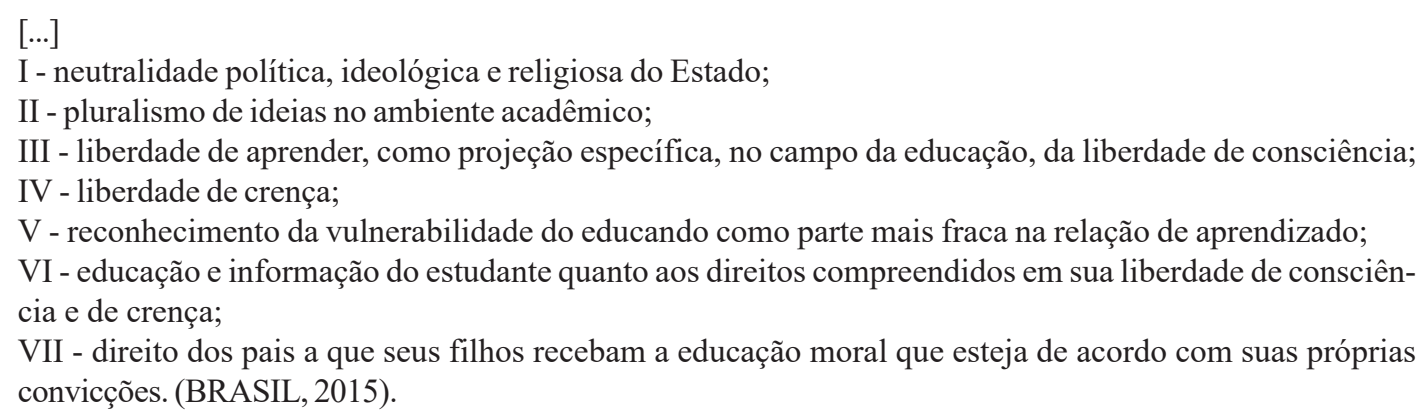

O projeto aponta ainda que, o estudante deve ser entendido como parte vulnerável nas relações de aprendizagem e deve ser vedado o ensino de conteúdos que possam entrar em conflito com a orientação política, as crenças religiosas e princípios morais ensinados pelos seus pais ou responsáveis - restringindo assim a atuação do Estado (via Sistema Educacional) aos limites de alcance da esfera privada da instituição familiar.

Eixos temáticos como estudos de gênero, das diversidades socioculturais, debates sobre os direitos de minorias sociais, direitos humanos, história e cultura afro-brasileiras e indígenas, relações de poder e desigualdades sociais, conteúdos políticos - entre outros, que compõem em grande medida o currículo da disciplina de Sociologia - são frequentemente criticados e associados à noção de doutrinação ideológica nas publicações realizadas pela página da ESP, como se verá mais adiante.

Não se trata aqui de buscar uma relação imediata entre as proposições da organização Escola sem Partido e a possibilidade de retirada da obrigatoriedade da Sociologia no currículo do Ensino Médio, mas sim de buscar compreender o modo como a organização aborda a questão do ensino de Sociologia e as possíveis implicações das pautas do movimento para seu currículo e à sociedade brasileira, por consequência.

\section{Escola sem Partido, ensino de sociologia e currículo}

A questão problematizada por este trabalho refere-se ao modo como o ensino da disciplina de Sociologia no Ensino Médio é caracterizado a partir das perspectivas compartilhadas por membros do movimento Escola sem Partido. Para dar conta dela, o trabalho utiliza-se da técnica da pesquisa documental, aplicada aos conteúdos disponíveis em meios de comunicação social (impressos e online), tais como as produções e publicações divulgadas pela página da organização, bem como entrevistas e textos vinculados ao movimento que foram publicizados em revistas e jornais.

Ao utilizar as publicações do site da Escola sem Partido, matérias de jornais e revistas impressas e eletrônicas, entrevistas e artigos do movimento, devemos levar em consideração que se tratam de fontes de caráter documental, que a partir de Moreira (2005, p. 272), podem ser classificadas como secundárias:

As fontes da análise documental frequentemente são de origem secundária, ou seja, constituem conhecimento, dados ou informação já reunidos ou organizados. São fontes secundárias a mídia impressa (jornais, revistas, boletins, almanaques, catálogos) e a eletrônica (gravações magnéticas de som e vídeo, gravações digitais de áudio e imagem) e relatórios técnicos. 
Mesmo no caso das entrevistas e artigos de opinião de autoria dos colaboradores da ESP, as fontes são consideradas secundárias, pois não há como garantir que tais conteúdos não tenham sido alterados, recortados, ou ainda, que tenha ocorrido algum erro por parte das mídias responsáveis por sua publicação. A análise dessas fontes documentais secundárias, tecida ao longo deste trabalho, apoia-se em contribuições da Análise Crítica do Discurso (ACD), que, de acordo com Fairclough e Melo (2012), tem por objetivo tomar o discurso enquanto relação dialética entre seus elementos estruturais e a ação discursiva dos sujeitos. Cabe aqui fazer a ressalva de que não é pretensão deste trabalho aplicar todos os procedimentos técnicos da ACD aos discursos, e sim levar em consideração as relações entre texto, prática discursiva e prática social, como apontam Fairclough e Melo (2012). Como qualquer análise discursiva, não se trata de chegar a uma verdade ou a um único resultado válido, mas de formular uma interpretação entre as várias possíveis.

Partindo da perspectiva analítica foucaultiana, é possível afirmar que todas as relações sociais, práticas e ações discursivas não são apenas integradas às relações de poder. Mais que isso, para Foucault (1998) são elas próprias disputas por poder e dominação - pois carregam tais intencionalidades, independentemente do Estado. O autor entende o poder como algo "[...] que não se encontra somente nas instâncias superiores da censura, mas que penetra muito profundamente, muito sutilmente em toda a trama da sociedade" (FOUCAULT, 2007, p. 42). Além disso, suas contribuições acerca das relações entre as formas de saber e poder permitem pensar o sistema educacional enquanto espaço de oposições e de lutas sociais. A primeira fonte que analisamos é a do próprio fundador e coordenador da ESP, o advogado Miguel Nagib, durante entrevista concedida à revista Profissão Mestre em 2010. Ao ser indagado sobre sua visão em relação à obrigatoriedade do ensino de Sociologia (e de Filosofia) no currículo do Ensino Médio, Nagib responde:

Vejo com muita preocupação. Se a História e a Geografia já serviam de plataforma para a militância ideológica, imagine o que vai acontecer com a Filosofia e a Sociologia! Vai acontecer, não! Já está acontecendo. Veja a opinião do sociólogo Simon Schwartzman sobre a proposta curricular para o programa de sociologia para o nível médio do Rio de Janeiro: "É um conjunto desastroso de ideias gerais, palavras de ordem e ideologias mal disfarçadas que confirmam as piores apreensões dos que, como eu, sempre temeram esta inclusão obrigatória da sociologia no currículo escolar". Se o currículo está desse jeito, imagine o conteúdo das aulas! (ESCOLA SEM PARTIDO, [200-?b]).

Em primeiro lugar, podemos destacar que a palavra preocupação evoca o sentido de temor ou de apreensão, o que indicaria que para o entrevistado a disciplina não deveria ser obrigatória devido ao problema da doutrinação ideológica. É possível perceber também, que, de acordo com Nagib, as disciplinas escolares podem ser classificadas em diferentes graus de propensão à militância e à doutrinação ideológica. Fica claro em seu discurso que, para ele, as disciplinas da área de humanas são mais frequentemente associadas à ideia de doutrinação e que as disciplinas de Filosofia e de Sociologia seriam ainda mais propensas a isso. Ao dizer "[...] imagine o que vai acontecer [...]" (ESCOLA SEM PARTIDO, [200-b]) Nagib demonstra não estar atento à questão colocada pelo entrevistador, que se refere à Lei $n^{\circ}$ 11.684 de 2008 e, logo em seguida faz sua correção.

No entanto, a correção é utilizada para afirmar que estas disciplinas já estariam servindo de base para uma doutrinação ideológica no Ensino Médio. Em sua fala, Nagib faz referência ao texto de Simon Schwartzman (2010), sobre o currículo de Sociologia para o Ensino Médio do Rio de Janeiro, para afirmar o teor ideológico e enviesado do currículo da disciplina. Esta menção ao sociólogo é especialmente importante, uma vez que o mesmo alega que sempre temeu uma inclusão obrigatória da disciplina. $\mathrm{O}$ fato de apoiar-se no posicionamento de um sociólogo demonstra a intenção de dar legitimidade e um tom de imparcialidade ao discurso.

Além disso, no texto ao qual Nagib se refere, Schwartzman (2010) afirma que no currículo carioca de Sociologia do Ensino Médio:

[...] sobram bobagens como "compreender e valorizar as diferentes manifestações culturais de etnias, raças (negra, indígena, branca) e segmentos sociais, agindo de modo a preservar o direito à diversidade enquanto princípio estético [...] que pode incentivar a tolerância, mas que em alguns casos pode gerar conflitos" [...].

O que demonstra uma posição contrária a uma abordagem interculturalista. A segunda fonte analisada é o artigo de Marcelo Bortoloti, publicado na Revista Veja, edição de 31 de março de 2010 e disponibilizado no site da ESP que discute a obrigatoriedade do ensino de Sociologia e Filosofia, afirmando que as disciplinas estariam a serviço da doutrinação ideológica nas escolas. No caso da Sociologia, o problema estaria no predomínio do marxismo e seria resultado de um enviesamento dos próprios cursos superiores de Ciências Sociais. Sobre a obrigatoriedade das disciplinas, Bortoloti (2010) afirma que: 
Ao obrigar as escolas a ensinar sociologia e filosofia a todos os alunos, o Brasil se junta à maioria dos países da América Latina - e se distancia dos mais avançados em sala de aula, que oferecem essas disciplinas apenas como eletivas. Deixá-las de fora da grade fixa é uma decisão que se baseia no que a experiência já provou.

O texto de Bortoloti não só reforça a preocupação de Miguel Nagib e o temor de Schwatzman, como associa a obrigatoriedade das disciplinas à ideia de um atraso na educação, quadro no qual o autor situa o Brasil e a maioria dos países da América Latina. Em contrapartida, países tidos como mais avançados ofertariam as disciplinas de modo eletivo. A narrativa prossegue, com a afirmação de que o Brasil não está preparado para tais disciplinas devido às deficiências básicas na educação.

Estas duas análises demonstram que, apesar da obrigatoriedade de o ensino de Sociologia ser vista de modo negativo, a disciplina é admitida, contudo há recorrência da oposição ao marxismo, socialismo e ao materialismo histórico-dialético nas perspectivas analisadas. Além do próprio Marx, intelectuais marxistas nacionais ou internacionais das Ciências Sociais, como Engels, Gramsci e Freire, são colocados em descrédito em diversas publicações.

As tentativas de colocar intelectuais em descrédito podem ser compreendidas a partir de Habermas (1987), em sua discussão sobre o esgotamento das utopias e teorias sociais após meados dos anos 70, com a Crise do Estado de Bem-Estar Social e a ascensão de grupos neoconservadores (neoliberais). Para ele um dos processos típicos desta ascensão neoconservadora estaria na operação da política cultural em duas frentes: (1) um esforço em desacreditar intelectuais considerados ameaçadores para a ordem vigente na sociedade do trabalho; (2) Fomento da cultura tradicional, do patriotismo, da moralidade convencional e da religião burguesa. (HABERMAS, 1987).

A Sociologia é reconhecida enquanto área do conhecimento nos textos e discursos vinculados a colaboradores do Escola sem Partido. Há inclusive professores de Sociologia e sociólogos tanto nas referências dos textos quanto entre colaboradores da organização, como por exemplo, o professor Bráulio Porto de Matos (UnB), que em seu texto demonstra simpatia pelas análises de Olavo de Carvalho e também pela proposta de Lei $\mathrm{n}^{\circ}$ 6.003/2013 (BRASIL, 2013), do deputado Izalci Lucas, abordada anteriormente neste trabalho.

O que se percebe nas publicações do site é que há por parte dos colaboradores da ESP uma insatisfação com a ausência de autores positivistas e liberais, o que caracterizaria o predomínio de uma Sociologia esquerdista no Brasil. A Sociologia que a organização admite seria aquela pautada pelo rigor cientificista, enquadrada em paradigmas nomotéticos das Ciências Sociais.

Quanto aos currículos, temáticas, relativas à questão das diversidades socioculturais e às relações sociais de poder, são associadas pela ESP ao conceito de doutrinação ideológica esquerdista e seriam impostas ao sistema educacional brasileiro através do Ministério da Educação (MEC) por meio de políticas educacionais, materiais didáticos, sistemas de avaliação, como, por exemplo, o ENEM e pelos currículos disciplinares.

Esses mesmos conteúdos relativos às diversidades são o motivo da oposição ao atual documento da Base Nacional Comum Curricular (BNCC), como demonstra o artigo de opinião produzido pelo coordenador da ESP e publicado pela Gazeta do Povo em janeiro de 2016:

Na sala de aula, terão de estudar os mundos ameríndios, africanos e afro-brasileiros; interpretar os movimentos sociais negros e quilombolas; valorizar e promover o respeito às culturas africanas e afro-americanas. É um assombro. Menos comentada, mas não menos importante, é a presença da famigerada ideologia de gênero. Como já se adivinhava, a perspectiva de gênero - cuja inclusão, nos planos de educação, foi rejeitada de maneira veemente pela quase totalidade das nossas casas legislativas - atravessa toda a proposta do MEC. (NAGIB, 2016).

Interessa de modo especial a esta pesquisa o fato de que as temáticas consideradas como bobagens e assombrosas possuem relação direta com os componentes das diretrizes curriculares da disciplina de Sociologia no Ensino Médio. A questão do respeito e reconhecimento das diversidades socioculturais é associada ao crime de doutrinação ideológica e há uma postura de desconfiança da prática educacional docente. 
As proposições da ESP e as perspectivas disseminadas pela organização são frequentemente vistas por seus opositores como tentativas de cerceamento e censura da liberdade de expressão na prática docente, o que na realidade não estaria assegurando uma pluralidade de ideias como supõe o projeto de Lei $n^{\circ} 867$ de 2015 (BRASIL, 2015). Ao contrário, operariam em favor da despolitização dos conteúdos curriculares, enviesando os mesmos em favor das desigualdades, das hegemonias já consolidadas e das injustiças social e historicamente construídas.

Ao abordar o modo como o trabalho docente foi sistematicamente controlado e atacado durante o período da ditadura militar no Brasil, Salles e Stampa (2016, p. 184) citam o Movimento Escola sem Partido como mais uma das tentativas de criminalização e deslegitimação da prática educativa, revelando assim a fragilidade e inconclusão de nossa transição democrática:

[...] cabe registrar os debates que se intensificam na Câmara dos Deputados, nas Assembleias Legislativas e em diversas Câmaras de Vereadores, onde o movimento Escola sem Partido propugna "por uma lei contra o abuso da liberdade de ensinar". Tudo indica que os defensores de tal proposta pretendem, na verdade, controlar e despolitizar o trabalho docente, determinando o que pode ou não ser ensinado, tal como no período ditatorial.

A persistência e refluxo dos esforços em prol do controle e criminalização da prática docente atestam, segundo os autores, sua centralidade para a formação do cidadão crítico e para instrumentalizar a análise das contradições de classe, problemas e desigualdades sociais. De acordo com Berger (1986), a peculiaridade da perspectiva da Sociologia consiste em seu olhar crítico lançado sob a realidade social, capaz de ultrapassar as fachadas das estruturas da sociedade. Os métodos da análise sociológica permitem superar o nível das aparências e as versões oficiais dos fatos sociais, aprofundando assim as interpretações sobre o mundo social.

No mesmo sentido, Mills (1975) busca pontuar características que tornam a abordagem sociológica específica, associando-a ao conceito de imaginação sociológica (MILLS, 1975), que se refere à possibilidade de transformação das formas de consciência dos sujeitos sociais e de seu modo de perceber a realidade social e se posicionar em sua vida cotidiana.

\section{Considerações finais}

Apesar da autoafirmação de um apartidarismo político e da pretensa neutralidade do ensino que embasaria as pautas da ESP, é possível identificar com facilidade, congruências político-ideológicas entre seus membros, que se opõem contundentemente aos posicionamentos políticos de esquerda e à abordagem de certos temas pontuais: política contemporânea, diversidade religiosa, educação sexual e estudos de gênero, direitos humanos, cultura e história afro-brasileira, ditadura militar brasileira (1964-1985), entre outros.

Percebe-se, assim, que a luta empreendida pela ESP não se encontra restrita ao embate anticomunista, se expandindo para o combate da fomentação tanto da valorização do pluralismo político-cultural, quanto de uma perspectiva política crítica que contradiga os princípios que embasam a visão de mundo da organização. Neste sentido a obrigatoriedade da Sociologia e os currículos utilizados podem ser vistos como uma ameaça.

Tanto para Berger (1986) quanto para Mills (1975), a Sociologia possui um papel fundamental para a desmistificação da realidade social epidérmica, para o ato de adquirir a consciência de si mesmo e do contexto social no qual se está inserido. Tais processos possibilitariam mudanças nas visões de mundo dos indivíduos e estariam fortemente vinculados ao projeto maior de uma transformação da realidade social.

As lutas e embates políticos ao longo da História revelam o potencial da disciplina para a instrumentalização dos estudantes no sentido da análise crítica da realidade social e do fomento de questionamentos da ordem social estabelecida. Por último, os conteúdos e o currículo vinculados à disciplina de Sociologia podem fomentar junto aos estudantes a desmistificação das aparências do mundo social, bem como, estimular uma conscientização de si e do lugar que ocupa na sociedade, capacidade necessária para que possa (ou não) intervir em sua respectiva realidade local e na sociedade brasileira.

\section{Referências}

BERGER, P. L. Perspectivas sociológicas: uma visão humanística. 23. ed. Petrópolis: Vozes, 1986.

BORTOLOTI, M. Ideologia na cartilha. Veja, [S. l.], 31 mar. 2010. Disponível em: https://web.archive.org/web/20121024213638/ http://veja.abril.com.br/310310/ideologia-cartilha-p-116.shtml. Acesso em: 12 jul. 2019. 
BRASIL. Câmara dos Deputados. Projeto de Lei n 867, de 2015. Brasília, DF: Câmara dos Deputados, 2015. Disponível em: https:/ /www.camara.leg.br/proposicoesWeb/prop_mostrarintegra;jsessionid=375C7

2096AFD87644868A98ED8436064.proposicoesWebExterno2? codteor=1317168\&filename=Avulso+-PL+867/2015. Acesso em: 12 jul. 2019.

BRASIL. Decreto $n^{\circ} 16.782-A$, de 13 de janeiro de 1925. Estabelece o concurso da União para a difusão do ensino primário, organiza o Departamento Nacional do Ensino, reforma o ensino secundário e o superior e dá outras providencias. Brasília, DF: Presidência da República, [1991]. Disponível em: http://www.planalto.gov.br/ccivil_03/decreto/1910-1929/D16782aimpressao.htm. Acesso em: 12 jul. 2019.

BRASIL. Lei $n^{\circ}$ 4.024, de 20 de dezembro de 1961. Fixa as Diretrizes e Bases da Educação Nacional. Brasília, DF: Presidência da República, [2019a]. Disponível em: http://www.planalto.gov.br/ccivil_03/LEIS/L4024.htm. Acesso em: 12 jul. 2019.

BRASIL. Lei $n^{\circ}$ 9.394, de 20 de dezembro 1996. Estabelece as diretrizes e Bases da Educação Nacional. Brasília, DF: Presidência da República, [2019b]. Disponivel em: http://www.planalto.gov.br/ccivil_03/leis/L9394.htm. Acesso em: 31 jan. 2019.

BRASIL. Lei $n^{\circ} 11.684$, de 02 de junho de 2008. Altera o art. 36 da Lei $n^{\circ}$ 9.394, de 20 de dezembro de 1996. Estabelece as diretrizes e bases da educação nacional, para incluir a Filosofia e a Sociologia como disciplinas obrigatórias nos currículos do ensino médio. Brasília, DF: Presidência da República, [2008]. Disponível em: http://www.planalto.gov.br/ccivil_03/_Ato2007-2010/2008/Lei/ L11684.htm. Acesso em: 31 jan. 2019.

BRASIL. Ministério da Educação. Parecer CNE/CEB n 38 de 2006. Inclusão obrigatória das disciplinas de Filosofia e Sociologia no currículo do Ensino Médio. Brasília, DF: Ministério da Educação, 2006. Disponível em: http://portal.mec.gov.br/cne/arquivos/pdf/ pceb038_06.pdf. Acesso em: 31 jan. 2019.

BRASIL. Ministério da Educação. Parâmetros Curriculares Nacionais: ensino médio: parte I - bases legais. Brasília, DF: Ministério da Educação, 2000a. Disponível em: http://portal.mec.gov.br/seb/arquivos/pdf/blegais.pdf. Acesso em: 12 jul. 2019.

BRASIL. Ministério da Educação. Resolução CEB n. 2. Institui as Diretrizes Curriculares Nacionais para o Ensino Fundamental. [Brasília, DF], 7 abr. 1998. Disponível em: http://portal.mec.gov.br/index.php?option=com_docman\&view=download\&alias=16261rceb02-98\&category_slug=agosto-2014-pdf\&Itemid=30192. Acesso em: 12 jul. 2019.

BRASIL. Senado Federal. Projeto de Lei da Câmara PLC n 9, de 2000. Altera o artigo 36 da Lei $n^{\circ} 9394$, de 20 de dezembro de 1996, que estabelece as diretrizes e bases da educação nacional. Diário do Senado Federal, Brasília, DF, 18 abr. 2000b. Disponível em: https://legis.senado.leg.br/diarios/BuscaDiario?codDiario=6818\&paginaDireta=07400. Acesso em: 12 jul. 2019.

BRASIL. Câmara dos Deputados. Projeto de Lei PL $n^{\circ}$ 6003/2013. Altera os arts. $9^{\circ}, 35$ e 36 da Lei n 9.394, de 20 de dezembro de 1996, de diretrizes e bases da educação nacional. Brasília, DF, 17 jul. 2013. Disponível em: https://www.camara.leg.br/proposicoesWeb/ fichadetramitacao?idProposicao=585581. Acesso em: 12 jul. 2019.

BRASIL. Câmara dos Deputados. Projeto de Lei PL $n^{\circ}$ 867/2015. Inclui, entre as diretrizes e bases da educação nacional, o "Programa Escola sem Partido”. Brasília, DF, 23 mar. 2015. Disponível em: https://www.camara.leg.br/proposicoesWeb/ prop_mostrarintegra;jsessionid=375C72096AFD87644868A98ED8436064 .proposicoesWebExterno2? codteor=1317168\&filename=Avulso+PL+867/2015. Acesso em: 12 jul. 2019.

CIGALES, M. P.; ARRIADA, E. Algumas considerações sobre o ensino da sociologia na educação brasileira 1882-1942. Perspectivas Sociais, Pelotas, ano 2, n. 1, p. 86-100, mar. 2013.

ESCOLA SEM PARTIDO. Doutrinação pelo mundo. Escola sem Partido, [S. 1.], [200-?a]. Disponível em: http:// www.escolasempartido.org/doutrinacao-pelo-mundo. Acesso em: 24 jul. 2019.

ESCOLA SEM PARTIDO. Entrevista de Miguel Nagib à revista Profissão Mestre. Escola sem Partido, [S. 1.], [200-?b]. Disponivel em: http://escolasempartido.org/midia/395-entrevista-de-miguel-nagib-a-revista-profissao-mestre. Acesso em 12 jul. 2019.

FAIRCLOUGH, N.; MELO, I. Análise crítica do discurso como método em pesquisa social científica. Linha d’Água, v. 25, n. 2, p. $307-$ $329,2012$.

FOUCAULT, M. A ordem do discurso. 4. ed. São Paulo: Loyola, 1998.

FOUCAULT, M. Microfísica do poder. 24. ed. Rio de Janeiro: Edições Graal, 2007.

FRIGOTTO, G. Imposição da Mordaça aos Educadores. e-Mosaicos, Rio de Janeiro v. 5, n. 9, p. 11-13, jun. 2016.

HABERMAS, J. A nova intransparência: a crise do estado de bem-estar social e o esgotamento das energias utópicas. Novos estudos Cebrap, São Paulo, n. 18, p. 103-114, set. 1987.

MILLS, C. W. A Imaginação Sociológica. 4. ed. Rio de Janeiro: Zahar, 1975.

MORAES, A. C. Ensino de Sociologia: periodização e campanha pela obrigatoriedade. Cadernos Cedes, Campinas, v. 31, n. 85, p. 359382, set./dez. 2011.

MOREIRA, S. V. Análise documental como método e como técnica. In: BARROS, A.; DUARTE, J. (org.). Métodos e técnicas de pesquisa em comunicação. São Paulo: Atlas, 2005. p. 269-279.

NAGIB, M. Quem deve aprovar a BNCC? Gazeta do Povo, [S. 1.], 16 jan. 2016. Disponível em: https://web.archive.org/web/ 20170103132225/http://www.gazetadopovo.com.br/opiniao/artigos/quem-deve-aprovar-a-bncc-462lhgu7ev4ytnvq6r2vc0lio. Acesso em: 12 jul. 2019.

NAGIB, M. Quem somos. Escola sem Partido. [S. 1.], [200-?]. Disponível em: http://www.escolasempartido.org/quem-somos. Acesso em: 12 jul. 2019. 
NAGIB, M. Entrevista do coordenador do ESP ao site Portaberta (09.08.2008). [S. 1.], [2008]. Escola sem Partido. Disponivel em: http:// www.escolasempartido.org/midia- categoria/291-entrevista-do-coordenador-do-esp-ao-site-portaberta-09-08-2008. Acesso em: 31 jan. 2019. NUNES, N.; REZENDE, M. J. de. O ensino da educação moral e cívica durante a ditadura militar. In: SIMPÓSIO LUTAS SOCIAIS NA AMÉRICA LATINA TRABALHADORE(A)S EM MOVIMENTO: CONSTITUIÇÃO DE UM NOVO PROLETARIADO? 3., 2008, Londrina. Anais [...]. Londrina: Universidade Estadual de Londrina, 2008. Disponível em: http://www.uel.br/grupo-pesquisa/gepal/ terceirosimposio/natalynunes.pdf. Acesso em: 31 jan. 2019.

PARANÁ. Secretaria de Estado da Educação do Paraná. Diretrizes Curriculares Estaduais da Educação Básica: Sociologia. Curitiba: Secretaria de Estado da Educação do Paraná, 2008. Disponível em: http://www.educadores.diaadia.pr.gov.br/arquivos/File/diretrizes/ dce_socio.pdf. Acesso em: 12 jul. 2019.

PARANÁ. [Constituição (1989)]. Lei Ordinária no 15.228, 25 de julho de 2006. Institui as disciplinas de filosofia e de sociologia como disciplinas obrigatórias na grade curricular do

ensino médio do estado do Paraná, conforme especifica. Curitiba: Assembleia Legislativa, [2006]. Disponivel em: http:// www.leisestaduais.com.br/pr/lei-ordinaria-n-15228-2006-parana-institui-as-disciplinas-de-filosofia-e-de-sociologia-como-disciplinasobrigatorias-na-grade-curricular-do-ensino-medio-do-estado-do-parana-conforme-especifica. Acesso em: 31 jan. 2019.

RAMALHO, V. C. V. S. O discurso da imprensa brasileira sobre a invasão anglo-saxônica ao Iraque. 2005. Dissertação (Mestrado em Linguística) - Instituto de Letras, Universidade de Brasília, Brasília, DF, 2005.

SALLES, M.; STAMPA, I. Ditadura militar e trabalho docente. Trabalho Necessário, ano 14, n. 23, p. 166-185, 2016.

SCHWARTZMAN, S. O currículo de sociologia para o ensino médio no Rio de Janeiro. Simon’s Site. [S. 1.], 7 mar. 2010. Disponível em: http://www.schwartzman.org.br/sitesimon/?p=1587\&lang=pt-br. Acesso em: 12 jun. 2019.

SILVA, I. F. A sociologia no ensino médio: os desafios institucionais e epistemológicos para a consolidação da disciplina. Cronos, Natal, v. 8, n. 2, p. 403-427, jul./dez. 2007.

SILVA, I. F. O ensino das ciências sociais. Sociologia no Brasil: histórico e perspectivas. In: MORAES, A. C. de. (coord.). Coleção explorando o ensino: sociologia. Brasília, DF: Ministério da Educação, 2010. v. 15, p. 15-44.

SCHNEIDER, C. M.; TAVARES, M. da S. Ciência em pauta: as estratégias discursivas das revistas superinteressante e galileu. Iniciacom, v. 5, n. 2, p. 1-19, out. 2013.

VARGAS, F. E. B. O ensino da Sociologia: dilemas de uma disciplina em busca de reconhecimento. [Pelotas]: Universidade Federal de Pelotas, [ca. 2010]. Disponivel em: https://wp.ufpel.edu.br/franciscovargas/files/2011/10/ARTIGO-O-Ensino-da-Sociologia.pdf. Acesso em: 31 jan. 2019.

\section{Ana Cláudia Rodrigues de Oliveira}

anaoliveira.uel@gmail.com

Mestrado em Ciências Sociais pela Universidade Estadual de Londrina (UEL).

Docente de Sociologia no Ensino Médio pela Secretaria de Estado da Educação do Paraná (SEED-PR).

\section{SEED-PR}

Av. Maringá, 290

CEP 86060-000 - Campo Belo, Londrina, Paraná, Brasil

\section{Fabio Lanza}

lanza1975@gmail.com

Pós-Doutorado em Ciências Sociais pela Pontifícia Universidade Católica de São Paulo (PUC/SP).

Professor Adjunto da Universidade Estadual de Londrina (UEL).

\section{UEL}

Centro de Letras e Ciências Humanas

Rod. Celso Garcia Cid-Km 380-PR 445 - Campus Universitário

CEP 86051-990 - Londrina, Paraná, Brasil

\section{Letícia Jovelina Storto}

leticiajstorto@gmail.com

Pós-Doutorado em Educação pela Universidade Estadual de Ponta Grossa (UEPG).

Professora adjunta da Universidade Estadual do Norte do Paraná (UENP). 


\section{UENP}

PR 160, Km 0 (saída para Leópolis) - Campus Universitário

CEP 86300-000 - Cornélio Procópio, Paraná, Brasil

\section{Agência financiadora}

Não se aplica.

\section{Contribuições dos autores}

A primeira autora foi orientada pelos dois outros autores em pesquisas de pós-graduação, resultando em um trabalho que foi adaptado para esta publicação. Todos os autores contribuíram para a escrita deste artigo e sua submissão à Revista Katálysis.
Aprovação por Comitê de Ética e consentimento para participação

Não se aplica.

\section{Consentimento para publicação}

Não se aplica.

Conflito de interesses

Não há conflito de interesses. 